\title{
Convergence theorems of a three-step iteration method for a countable family of pseudocontractive mappings
}

\section{Qingqing Cheng, Yongfu Su* and Jingling Zhang}

\section{"Correspondence:}

suyongfu@tjpu.edu.cn

Department of Mathematics, Tianjin

Polytechnic University, Tianjin,

300387, China

\begin{abstract}
The purpose of this paper is to construct a three-step iteration method (as follows) and obtain the convergence theorem for a countable family of Lipschitz pseudocontractive mappings in Hilbert space $H$. For the iteration format,

$$
\left\{\begin{array}{l}
z_{n}=\left(1-\gamma_{n}\right) x_{n}+\gamma_{n} T_{n} x_{n}, \\
y_{n}=\left(1-\beta_{n}\right) x_{n}+\beta_{n} T_{n} z_{n}, \\
x_{n+1}=\left(1-\alpha_{n}\right) x_{n}+\alpha_{n} T_{n} y_{n},
\end{array}\right.
$$

under suitable conditions, we prove that the sequence $\left\{x_{n}\right\}$ generated from above converges strongly to a common fixed point of $\left\{T_{n}\right\}_{n \geq 1}$. The results obtained in this paper improve and extend previous results that have been proved for this class of nonlinear mappings.

MSC: $47 \mathrm{H} 05 ; 47 \mathrm{H09} ; 47 \mathrm{H} 10$

Keywords: Lipschitz pseudocontractive mapping; uniformly closed; monotone mapping; strong convergence; common fixed point
\end{abstract}

\section{Introduction}

Let $C$ be a nonempty subset of $H$. A mapping $T: C \rightarrow H$ is said to be nonexpansive, if

$$
\|T x-T y\| \leq\|x-y\|, \quad \forall x, y \in C
$$

A mapping $T: C \rightarrow H$ is called $\alpha$-strictly pseudocontractive in the terminology of Browder and Petryshyn [1] if for all $x, y \in C$ there exists $\alpha>0$ such that

$$
\langle T x-T y, j(x-y)\rangle \leq\|x-y\|^{2}-\alpha\|x-y-(T x-T y)\|^{2}
$$

Without loss of generality, we may assume that $\alpha \in(0,1)$. If $I$ denotes the identity operator, then (1.2) can be rewritten as

$$
\langle(I-T) x-(I-T) y, j(x-y)\rangle \geq \alpha\|(I-T) x-(I-T) y\|^{2} .
$$

(c) 2013 Cheng et al.; licensee Springer. This is an Open Access article distributed under the terms of the Creative Commons Attribution License (http://creativecommons.org/licenses/by/2.0), which permits unrestricted use, distribution, and reproduction in any medium, provided the original work is properly cited. 
A mapping $T$ is called pseudocontractive if

$$
\langle T x-T y, x-y\rangle \leq\|x-y\|^{2} .
$$

Note that inequality (1.3) can be equivalently written as

$$
\|T x-T y\|^{2} \leq\|x-y\|^{2}+\|(I-T) x-(I-T) y\|^{2}, \quad \forall x, y \in C .
$$

Apart from their being an important generalization of nonexpansive mappings and $\alpha$-strict pseudocontractive mappings, interest in pseudocontractive mappings stems mainly from their firm connection with the important class of nonlinear monotone mappings, where a mapping $A$ with domain $D(A)$ and range $R(A)$ in $H$ is called monotone if the inequality

$$
\|x-y\| \leq\|x-y+s(A x-A y)\|
$$

holds for every $x, y \in D(A)$ and for all $s>0$. We observe that $A$ is monotone if and only if $T:=I-A$ is pseudocontractive, and thus a zero of $A, N(A):=\{x \in D(A): A x=0\}$, is a fixed point of $T, F(T):=\{x \in D(T): T x=x\}$. It is now well known (see, e.g., [2]) that if $A$ is monotone then the solutions of the equation $A x=0$ correspond to the equilibrium points of some evolution systems. Consequently, considerable research efforts, especially within the past 20 years or so, have been devoted to iterative methods for approximating fixed points of $T$ when $T$ is pseudocontractive (see, for example, [3-5] and the references contained therein).

The most general iterative algorithm for nonexpansive mappings studied by many authors is the following:

$$
x_{0} \in C, \quad x_{n+1}=\left(1-\alpha_{n}\right) x_{n}+\alpha_{n} T x_{n}, \quad n \geq 0,
$$

where $\left\{\alpha_{n}\right\}_{n \geq 0} \subset(0,1)$ and satisfies the following additional assumptions: (i) $\lim _{n \rightarrow \infty} \alpha_{n}=$ 0 ; (ii) $\sum_{n=1}^{\infty} \alpha_{n}=\infty$, the sequence $\left\{x_{n}\right\}_{n \geq 1}$ generated by (1.5) is generally referred to as the Mann iteration scheme in the light of Mann [6].

The Mann iteration process does not generally converge to a fixed point of $T$ even when the fixed point exists. If, for example, $C$ is a nonempty, closed, convex and bounded subset of a real Hilbert space, $T: C \rightarrow C$ is nonexpansive, and the Mann iteration process is defined by (1.5) with (i) $\lim _{n \rightarrow \infty} \alpha_{n}=0$; (ii) $\sum_{n=1}^{\infty} \alpha_{n}=\infty$, one can only prove that the sequence is an approximate fixed point sequence, that is, $\left\|x_{n}-T x_{n}\right\| \rightarrow 0$ as $n \rightarrow \infty$. To get the sequence $\left\{x_{n}\right\}_{n \geq 1}$ to converge to a fixed point of $T$ (when such a fixed point exists), some type of compactness condition must be additionally imposed either on $C$ (e.g., $C$ is compact) or on $T$.

Later, some authors tried to prove convergence of Mann iteration scheme to a fixed point of a much more general and important class of Lipschitz pseudocontractive mappings. But, in 2001, Chidume and Mutangadura [7] gave an example of a Lipschitz pseudocontractive self-map of a compact convex subset of a Hilbert space with a unique fixed point for which no Mann sequence converges. Consequently, for this class of maps, the Mann sequence may not converge to a fixed point of Lipschitz pseudocontractive mappings even when $C$ is a compact convex subset of $H$. 
In 1974, Ishikawa [8] introduced an iteration process, which in some sense is more general than that of Mann and which converges to a fixed point of a Lipschitz pseudocontractive self-map $T$ of $C$. The following theorem is proved.

Theorem IS [8] If C is a compact convex subset of a Hilbert space $H, T: C \rightarrow C$ is a Lipschitz pseudocontractive mapping and $x_{0}$ is any point of $C$, then the sequence $\left\{x_{n}\right\}$ converges strongly to a fixed point of $T$, where $\left\{x_{n}\right\}$ is defined iteratively for each integer $n \geq 0$ by

$$
\left\{\begin{array}{l}
y_{n}=\left(1-\beta_{n}\right) x_{n}+\beta_{n} T x_{n} \\
x_{n+1}=\left(1-\alpha_{n}\right) x_{n}+\alpha_{n} T y_{n}
\end{array}\right.
$$

where $\left\{\alpha_{n}\right\},\left\{\beta_{n}\right\}$ are sequences of positive numbers satisfying the conditions:

$$
\text { (i) } \quad 0 \leq \alpha_{n} \leq \beta_{n} \leq 1 ; \quad \text { (ii) } \quad \lim _{n \rightarrow \infty} \beta_{n}=0 ; \quad \text { (iii) } \quad \sum_{n=0}^{\infty} \alpha_{n} \beta_{n}=\infty \text {. }
$$

The iteration method of Theorem IS, which is now referred to as the Ishikawa iterative method has been studied extensively by various authors. But it is still an open question whether or not this method can be employed to approximate fixed points of Lipschitz pseudocontractive mappings without the compactness assumption on $C$ or $T$ (see, e.g., $[4,9,10])$.

In order to obtain a strong convergence theorem for pseudocontractive mappings without the compactness assumption, Zhou [11] established the hybrid Ishikawa algorithm for Lipschitz pseudocontractive mappings as follows:

$$
\left\{\begin{array}{l}
y_{n}=\left(1-\alpha_{n}\right) x_{n}+\alpha_{n} T x_{n}, \\
z_{n}=\left(1-\beta_{n}\right) x_{n}+\beta_{n} T y_{n}, \\
C_{n}=\left\{z \in C:\left\|z_{n}-z\right\|^{2} \leq\left\|x_{n}-z\right\|^{2}-\alpha_{n} \beta_{n}\left(1-2 \alpha_{n}-L^{2} \alpha_{n}^{2}\right)\left\|x_{n}-T x_{n}\right\|^{2}\right\} \\
Q_{n}=\left\{z \in C:\left\langle x_{n}-z, x_{0}-x_{n}\right\rangle \geq 0\right\}, \\
x_{n+1}=P_{C_{n} \cap Q_{n}} x_{0}, \quad n \in N .
\end{array}\right.
$$

He proved that the sequence $\left\{x_{n}\right\}$ defined by (1.8) converges strongly to $P_{F(T)} x_{0}$, where $P_{C}$ is the metric projection from $H$ into $C$. We observe that the iterative algorithm (1.7) generates a sequence $\left\{x_{n}\right\}$ by projecting $x_{0}$ onto the intersection of closed convex sets $C_{n}$ and $Q_{n}$ for each $n \geq 0$.

In 2009, Yao et al. [12] introduced the hybrid Mann algorithm as follows. Let $C$ be a nonempty, closed and convex subset of a real Hilbert space $H$. Let $T: C \rightarrow C$ be a $L$-Lipschitz pseudocontractive mapping such that $F(T) \neq \emptyset$. Assume that the sequence $\left\{\alpha_{n}\right\} \subset[a, b]$ for some $a, b \in\left(0, \frac{1}{1+L}\right)$. Then for $C_{1}=C$ and $x_{1}=P_{C_{1}} x_{0}$, they proved that the sequence $\left\{x_{n}\right\}$ defined by

$$
\left\{\begin{array}{l}
y_{n}=\left(1-\alpha_{n}\right) x_{n}+\alpha_{n} T x_{n} \\
C_{n+1}=\left\{z \in C_{n}:\left\|\alpha_{n}(I-T) y_{n}\right\|^{2} \leq 2 \alpha_{n}\left\langle x_{n}-z,(I-T) y_{n}\right\rangle\right\} \\
x_{n+1}=P_{C_{n+1}} x_{0}, \quad n \in N
\end{array}\right.
$$

converges strongly to $P_{F(T)} x_{0}$. 
More recently, Tang et al. [13] generalized algorithm (1.8) to the hybrid Ishikawa iterative process. Let $C$ be a nonempty, closed and convex subset of a real Hilbert space $H$. Let $T: C \rightarrow C$ be a Lipschitz pseudocontractive mapping. Let $\left\{\alpha_{n}\right\},\left\{\beta_{n}\right\}$ be a sequence in $[0,1]$. Suppose that $x_{0} \in H$. For $C_{1}=C$ and $x_{1}=P_{C_{1}} x_{0}$, define a sequence $\left\{x_{n}\right\}$ of $C$ as follows:

$$
\left\{\begin{aligned}
y_{n}= & \left(1-\alpha_{n}\right) x_{n}+\alpha_{n} T z_{n}, \\
z_{n}= & \left(1-\beta_{n}\right) x_{n}+\beta_{n} T x_{n}, \\
C_{n+1}= & \left\{z \in C_{n}:\left\|\alpha_{n}(I-T) y_{n}\right\|^{2} \leq 2 \alpha_{n}\left\langle x_{n}-z,(I-T) y_{n}\right\rangle\right. \\
& \left.+2 \alpha_{n} \beta_{n} L\left\|x_{n}-T x_{n}\right\| \cdot\left\|y_{n}-x_{n}+\alpha_{n}(I-T) y_{n}\right\|\right\}, \\
x_{n+1}= & P_{C_{n+1}} x_{0}, \quad n \in N .
\end{aligned}\right.
$$

Then they proved that the hybrid algorithm (1.9) strongly converges to a fixed point of Lipschitz pseudocontractive mappings. It is worth mentioning that the schemes in (1.7)(1.9) are not easy to compute. They involve computation of the intersection of $C_{n}$ and $Q_{n}$ for each $n \geq 1$.

Recently, Habtu Zegeye et al. [18] generalized algorithm (1.9) to Ishikawa iterative process (not hybrid) as follows. Let $C$ be a nonempty, closed and convex subset of a real Hilbert space $H$. Let $T_{i}: C \rightarrow C, i=1,2, \ldots, N$, be a finite family of Lipschitz pseudocontractive mappings with Lipschitzian constants $L_{i}$, for $i=1,2, \ldots, N$, respectively. Assume that the interior of $F:=\bigcap_{i=1}^{N} F\left(T_{i}\right)$ is nonempty. Let $\left\{x_{n}\right\}$ be a sequence generated from an arbitrary $x_{0} \in C$ by

$$
\left\{\begin{array}{l}
y_{n}=\left(1-\beta_{n}\right) x_{n}+\beta_{n} T_{n} x_{n}, \\
x_{n+1}=\left(1-\alpha_{n}\right) x_{n}+\alpha_{n} T_{n} y_{n} .
\end{array}\right.
$$

Under some conditions, $\left\{x_{n}\right\}$ converges strongly to $x^{*} \in F$.

Our concern now is the following: Is it possible to construct a three-step iteration method and obtain a convergence theorem for a countable family of pseudocontractive mappings?

It is our purpose in this paper to construct a three-step iteration method and obtain the convergence theorem for a countable family of pseudocontractive mappings provided that the interior of the common fixed points is nonempty. No compactness assumption is imposed either on one of the mappings or on $C$. The results obtained in this paper improve and extend the results of Theorem IS, Zhou [14], Yao et al. [12], Tang et al. [13] and Habtu Zegeye et al. [18].

\section{Preliminaries}

Let $C$ be a nonempty subset of a real Hilbert space $H$. The mapping $T: C \rightarrow H$ is called Lipschitz or Lipschitz continuous if there exists $L>0$ such that

$$
\|T x-T y\| \leq L\|x-y\|, \quad \forall x, y \in C .
$$

If $L=1$, then $T$ is called nonexpansive; and if $L<1$ then $T$ is called a contraction. It is easy to see from Eq. (2.1) that every contraction mapping is nonexpansive and every nonexpansive mapping is Lipschitz. 
A countable family of mapping $\left\{T_{n}\right\}_{n=1}^{\infty}: C \rightarrow H$ is called uniformly Lipschitz with Lipschitz constant $L_{n}>0, n \geq 1$, if there exists $0<L=\sup _{n \geq 1} L_{n}$ such that

$$
\left\|T_{n} x-T_{n} y\right\| \leq L\|x-y\|, \quad \forall x, y \in C, n \geq 1 .
$$

A countable family of mapping $\left\{T_{n}\right\}_{n=1}^{\infty}: C \rightarrow H$ is called uniformly closed if $x_{n} \rightarrow x^{*}$ and $\left\|x_{n}-T_{n} x_{n}\right\| \rightarrow 0$ imply $x^{*} \in \bigcap_{n=1}^{\infty} F\left(T_{n}\right)$.

In the sequel, we also need the following definition and lemma.

Let $H$ be a real Hilbert space. The function $\phi: H \times H \rightarrow R$ defined by

$$
\phi(x, y):=\|x-y\|^{2}=\|x\|^{2}-2\langle x, y\rangle+\|y\|^{2}, \quad \text { for } x, y \in H,
$$

is studied by Alber [15], Kamimula and Takahashi [16] and Riech [17].

It is obvious from the definition of the function $\phi$ that

$$
(\|x\|-\|y\|)^{2} \leq \phi(x, y) \leq(\|x\|+\|y\|)^{2}, \quad \text { for } x, y \in H .
$$

The function $\phi$ also has the following property:

$$
\phi(y, x)=\phi(y, z)+\phi(z, x)+2\langle z-y, x-z\rangle, \quad \text { for } x, y, z \in H .
$$

Lemma 2.1 Let $H$ be a real Hilbert space. Then for all $x, y \in H$ and $\alpha \in[0,1]$ the following inequality holds:

$$
\|\alpha x+(1-\alpha) y\|^{2}=\alpha\|x\|^{2}+(1-\alpha)\|y\|^{2}-\alpha(1-\alpha)\|x-y\|^{2} .
$$

Remark 2.2 We now give an example of a countable family of uniformly closed and uniformly Lipschitz pseudocontractive mappings with the interior of the common fixed points nonempty. Suppose that $X:=R$ and $C:=[-1,1] \subset R$. Let $\left\{T_{n}\right\}_{n \geq 1}: C \rightarrow C$ be defined by

$$
T_{n} x:= \begin{cases}x, & x \in[-1,0), \\ \left(\frac{1}{2^{n}}+\frac{1}{2}\right) x, & x \in[0,1] .\end{cases}
$$

Then we observe that $F:=\bigcap_{n=1}^{\infty} F\left(T_{n}\right)=[-1,0]$, and hence the interior of the common fixed points is nonempty.

Now, we show that $\left\{T_{n}\right\}_{n \geq 1}$ is a countable family of pseudocontractive mappings. Suppose that $C_{1}=[-1,0)$ and $C_{2}=[0,1]$. If $x, y \in C_{1}$, we have that

$$
\left\langle T_{n} x-T_{n} y, x-y\right\rangle=\langle x-y, x-y\rangle=|x-y|^{2} .
$$

If $x, y \in C_{2}$, we have that

$$
\begin{aligned}
\left\langle T_{n} x-T_{n} y, x-y\right\rangle & =\left\langle\left(\frac{1}{2^{n}}+\frac{1}{2}\right) x-\left(\frac{1}{2^{n}}+\frac{1}{2}\right) y, x-y\right\rangle \\
& =\left(\frac{1}{2^{n}}+\frac{1}{2}\right)|x-y|^{2} \\
& \leq|x-y|^{2} .
\end{aligned}
$$


If $x \in C_{1}, y \in C_{2}$, considering $\left(\frac{1}{2^{n}}-\frac{1}{2}\right) y(x-y)>0$, we have that

$$
\begin{aligned}
\left\langle T_{n} x-T_{n} y, x-y\right\rangle & =\left\langle x-\left(\frac{1}{2^{n}}+\frac{1}{2}\right) y, x-y\right\rangle \\
& =|x-y|^{2}-\left(\frac{1}{2^{n}}-\frac{1}{2}\right) y(x-y) \\
& \leq|x-y|^{2} .
\end{aligned}
$$

Therefore, from (2.5), (2.6) and (2.7) we obtain that $\left\{T_{n}\right\}_{n \geq 1}$ is a countable family of pseudocontractive mappings.

Next, we show that $\left\{T_{n}\right\}_{n \geq 1}$ is uniformly Lipschitz with Lipschitz constant $L=\sup _{n \geq 1} L_{n}=$ 2. If $x, y \in C_{1}$, we have that

$$
\left|T_{n} x-T_{n} y\right|=|x-y| \leq 2|x-y| .
$$

If $x, y \in C_{2}$, we have that

$$
\left|T_{n} x-T_{n} y\right|=\left(\frac{1}{2^{n}}+\frac{1}{2}\right)|x-y| \leq 2|x-y| .
$$

If $x \in C_{1}, y \in C_{2}$, we have that

$$
\begin{aligned}
\left|T_{n} x-T_{n} y\right| & =\left|x-\left(\frac{1}{2^{n}}+\frac{1}{2}\right) y\right| \\
& =\left|x-y-\frac{1}{2^{n}} y+\frac{1}{2} y\right| \\
& \leq|x-y|+\left(\frac{1}{2^{n}}+\frac{1}{2}\right) y \\
& \leq|x-y|+\left(\frac{1}{2^{n}}+\frac{1}{2}\right)|x-y| \\
& \leq 2|x-y| .
\end{aligned}
$$

Therefore, from (2.8), (2.9) and (2.10) we obtain that $\left\{T_{n}\right\}_{n \geq 1}$ is uniformly Lipschitz.

Finally, we show that $\left\{T_{n}\right\}_{n \geq 1}$ is uniformly closed.

If there exists $\left\{x_{n}\right\} \subset C_{1}$ such that $x_{n} \rightarrow x^{*} \in[-1,0]$, and $\left|x_{n}-T_{n} x_{n}\right|=0$, we observe that $[-1,0] \subset F$;

If there exists $\left\{x_{n}\right\} \subset C_{2}$ such that $x_{n} \rightarrow x^{*} \in[0,1]$, if and only if $x^{*}=0$, we have that $\left|x_{n}-T_{n} x_{n}\right|=0$, it is obvious that $0 \in F$;

If there exists $\left\{x_{n}\right\} \subset C$ :

(i) $\exists N$, as $n>N, x_{n} \in C_{2}$. The proof is the same as the proof of the second situation;

(ii) $\exists N$, as $n>N, x_{n} \in C_{1}$. The proof is the same as the proof of the first situation;

(iii) $\left\{x_{n_{k}}\right\} \subset C_{1},\left\{x_{n_{j}}\right\} \subset C_{2}$. If there exists $x_{n} \rightarrow x^{*}$, then we have that $x^{*}=0$. The proof is the same as the proof of the second situation. So, we can obtain that $\left\{T_{n}\right\}_{n \geq 1}$ is uniformly closed. 


\section{Main results}

Theorem 3.1 Let $C$ be a nonempty, closed and convex subset of a real Hilbert space $H$, let $\left\{T_{n}\right\}_{n=1}^{\infty}: C \rightarrow C$ be a countable family of uniformly closed and uniformly Lipschitz pseudocontractive mappings with Lipschitzian constants $L_{n}$, let $L:=\sup _{n \geq 1} L_{n}$. Assume that the interior of $F:=\bigcap_{n=1}^{\infty} F\left(T_{n}\right)$ is nonempty. Let $\left\{x_{n}\right\}$ be a sequence generated from an arbitrary $x_{0} \in C$ by the following algorithm:

$$
\left\{\begin{array}{l}
z_{n}=\left(1-\gamma_{n}\right) x_{n}+\gamma_{n} T_{n} x_{n}, \\
y_{n}=\left(1-\beta_{n}\right) x_{n}+\beta_{n} T_{n} z_{n}, \\
x_{n+1}=\left(1-\alpha_{n}\right) x_{n}+\alpha_{n} T_{n} y_{n},
\end{array}\right.
$$

where $\left\{\alpha_{n}\right\},\left\{\beta_{n}\right\},\left\{\gamma_{n}\right\} \subset(0,1)$ satisfying the following conditions: (i) $\alpha_{n} \leq \beta_{n} \leq \gamma_{n}, \forall n \geq 0$; (ii) $\liminf _{n \rightarrow \infty} \alpha_{n}=\alpha>0$; (iii) $\sup _{n \geq 1} \gamma_{n} \leq \gamma$ with $\gamma^{3} L^{4}+2 \gamma^{2} L^{3}+\gamma^{2} L^{2}+\gamma L^{2}+2 \gamma<1$. Then $\left\{x_{n}\right\}$ converges strongly to $x^{*} \in F$.

Proof Suppose that $p \in F$. Then from (3.1) and Lemma 2.1, we have that

$$
\begin{aligned}
\left\|x_{n+1}-p\right\|^{2}= & \left(1-\alpha_{n}\right)\left\|x_{n}-p\right\|^{2}+\alpha_{n}\left\|T_{n} y_{n}-p\right\|^{2}-\alpha_{n}\left(1-\alpha_{n}\right)\left\|x_{n}-T_{n} y_{n}\right\|^{2} \\
\leq & \left(1-\alpha_{n}\right)\left\|x_{n}-p\right\|^{2}+\alpha_{n}\left(\left\|y_{n}-p\right\|^{2}+\left\|y_{n}-T_{n} y_{n}\right\|^{2}\right) \\
& -\alpha_{n}\left(1-\alpha_{n}\right)\left\|x_{n}-T_{n} y_{n}\right\|^{2} \\
= & \left(1-\alpha_{n}\right)\left\|x_{n}-p\right\|^{2}+\alpha_{n}\left\|y_{n}-p\right\|^{2}+\alpha_{n}\left\|y_{n}-T_{n} y_{n}\right\|^{2} \\
& -\alpha_{n}\left(1-\alpha_{n}\right)\left\|x_{n}-T_{n} y_{n}\right\|^{2}, \\
\left\|y_{n}-p\right\|^{2}= & \left(1-\beta_{n}\right)\left\|x_{n}-p\right\|^{2}+\beta_{n}\left\|T_{n} z_{n}-p\right\|^{2}-\beta_{n}\left(1-\beta_{n}\right)\left\|x_{n}-T_{n} z_{n}\right\|^{2} \\
\leq & \left(1-\beta_{n}\right)\left\|x_{n}-p\right\|^{2}+\beta_{n}\left\|z_{n}-p\right\|^{2}+\beta_{n}\left\|z_{n}-T_{n} z_{n}\right\|^{2} \\
& -\beta_{n}\left(1-\beta_{n}\right)\left\|x_{n}-T_{n} z_{n}\right\|^{2}, \\
\left\|z_{n}-p\right\|^{2}= & \left(1-\gamma_{n}\right)\left\|x_{n}-p\right\|^{2}+\gamma_{n}\left\|T_{n} x_{n}-p\right\|^{2}-\gamma_{n}\left(1-\gamma_{n}\right)\left\|x_{n}-T_{n} x_{n}\right\|^{2} \\
\leq & \left(1-\gamma_{n}\right)\left\|x_{n}-p\right\|^{2}+\gamma_{n}\left\|x_{n}-p\right\|^{2}+\gamma_{n}\left\|x_{n}-T_{n} x_{n}\right\|^{2} \\
& -\gamma_{n}\left(1-\gamma_{n}\right)\left\|x_{n}-T_{n} x_{n}\right\|^{2} \\
= & \left\|x_{n}-p\right\|^{2}+\gamma_{n}^{2}\left\|x_{n}-T_{n} x_{n}\right\|^{2} .
\end{aligned}
$$

In addition, using (3.1), we have that

$$
\begin{aligned}
\left\|z_{n}-T_{n} z_{n}\right\|^{2}= & \left\|\left(1-\gamma_{n}\right)\left(x_{n}-T_{n} z_{n}\right)+\gamma_{n}\left(T_{n} x_{n}-T_{n} z_{n}\right)\right\|^{2} \\
= & \left(1-\gamma_{n}\right)\left\|x_{n}-T_{n} z_{n}\right\|^{2}+\gamma_{n}\left\|T_{n} x_{n}-T_{n} z_{n}\right\|^{2} \\
& -\gamma_{n}\left(1-\gamma_{n}\right)\left\|x_{n}-T_{n} x_{n}\right\|^{2} \\
\leq & \left(1-\gamma_{n}\right)\left\|x_{n}-T_{n} z_{n}\right\|^{2}+\gamma_{n} L^{2}\left\|x_{n}-z_{n}\right\|^{2} \\
& -\gamma_{n}\left(1-\gamma_{n}\right)\left\|x_{n}-T_{n} x_{n}\right\|^{2} \\
= & \left(1-\gamma_{n}\right)\left\|x_{n}-T_{n} z_{n}\right\|^{2}+\gamma_{n}^{3} L^{2}\left\|x_{n}-T_{n} x_{n}\right\|^{2} \\
& -\gamma_{n}\left(1-\gamma_{n}\right)\left\|x_{n}-T_{n} x_{n}\right\|^{2} \\
= & \left(1-\gamma_{n}\right)\left\|x_{n}-T_{n} z_{n}\right\|^{2}+\gamma_{n}\left(\gamma_{n}^{2} L^{2}+\gamma_{n}-1\right)\left\|x_{n}-T_{n} x_{n}\right\|^{2} .
\end{aligned}
$$


Substituting (3.4) and (3.5) into (3.3), we obtain that

$$
\begin{aligned}
\left\|y_{n}-p\right\|^{2} \leq & \left(1-\beta_{n}\right)\left\|x_{n}-p\right\|^{2}+\beta_{n}\left(\left\|x_{n}-p\right\|^{2}+\gamma_{n}^{2}\left\|x_{n}-T_{n} x_{n}\right\|^{2}\right) \\
& +\beta_{n}\left[\left(1-\gamma_{n}\right)\left\|x_{n}-T_{n} z_{n}\right\|^{2}+\gamma_{n}\left(\gamma_{n}^{2} L^{2}+\gamma_{n}-1\right)\left\|x_{n}-T_{n} x_{n}\right\|^{2}\right] \\
& \quad-\beta_{n}\left(1-\beta_{n}\right)\left\|x_{n}-T_{n} z_{n}\right\|^{2} \\
= & \left\|x_{n}-p\right\|^{2}+\beta_{n} \gamma_{n}\left(\gamma_{n}^{2} L^{2}+2 \gamma_{n}-1\right)\left\|x_{n}-T_{n} x_{n}\right\|^{2} \\
& +\beta_{n}\left(\beta_{n}-\gamma_{n}\right)\left\|x_{n}-T_{n} z_{n}\right\|^{2} .
\end{aligned}
$$

Since

$$
\begin{gathered}
\left\|y_{n}-T_{n} y_{n}\right\|^{2}=\left\|\left(1-\beta_{n}\right)\left(x_{n}-T_{n} y_{n}\right)+\beta_{n} T_{n} z_{n}-T_{n} y_{n}\right\|^{2} \\
=\left(1-\beta_{n}\right)\left\|x_{n}-T_{n} y_{n}\right\|^{2}+\beta_{n}\left\|T_{n} z_{n}-T_{n} y_{n}\right\|^{2} \\
\quad-\beta_{n}\left(1-\beta_{n}\right)\left\|x_{n}-T_{n} z_{n}\right\|^{2} \\
\leq \quad\left(1-\beta_{n}\right)\left\|x_{n}-T_{n} y_{n}\right\|^{2}+\beta_{n} L^{2}\left\|z_{n}-y_{n}\right\|^{2} \\
\quad-\beta_{n}\left(1-\beta_{n}\right)\left\|x_{n}-T_{n} z_{n}\right\|^{2} . \\
\left\|z_{n}-y_{n}\right\|=\left\|\left(1-\gamma_{n}\right) x_{n}+\gamma_{n} T_{n} x_{n}-\left(1-\beta_{n}\right) x_{n}-\beta_{n} T_{n} z_{n}\right\| \\
=\left\|\beta_{n} x_{n}-\gamma_{n} x_{n}+\gamma_{n} T_{n} x_{n}-\beta_{n} T_{n} z_{n}\right\| \\
=\left\|\left(\beta_{n}-\gamma_{n}\right) x_{n}-\left(\beta_{n}-\gamma_{n}\right) T_{n} x_{n}+\beta_{n}\left(T_{n} x_{n}-T_{n} z_{n}\right)\right\| \\
\leq \\
=\left(\gamma_{n}-\beta_{n}\right)\left\|x_{n}-T_{n} x_{n}\right\|+\beta_{n} L\left\|x_{n}-z_{n}\right\| \\
=\left(\gamma_{n}-\beta_{n}\right)\left\|x_{n}-T_{n} x_{n}\right\|+\beta_{n} \gamma_{n} L\left\|x_{n}-T_{n} x_{n}\right\| \\
=\left(\gamma_{n}-\beta_{n}+\beta_{n} \gamma_{n} L\right)\left\|x_{n}-T_{n} x_{n}\right\| .
\end{gathered}
$$

Then, substituting (3.8) into (3.7), we obtain that

$$
\begin{aligned}
\left\|y_{n}-T_{n} y_{n}\right\|^{2} \leq & \left(1-\beta_{n}\right)\left\|x_{n}-T_{n} y_{n}\right\|^{2}+\beta_{n} L^{2}\left(\gamma_{n}-\beta_{n}+\beta_{n} \gamma_{n} L\right)^{2}\left\|x_{n}-T_{n} x_{n}\right\|^{2} \\
& -\beta_{n}\left(1-\beta_{n}\right)\left\|x_{n}-T_{n} z_{n}\right\|^{2} .
\end{aligned}
$$

Substituting (3.6) and (3.9) into (3.2), we obtain that

$$
\begin{aligned}
\left\|x_{n+1}-p\right\|^{2} \leq & \left(1-\alpha_{n}\right)\left\|x_{n}-p\right\|^{2}+\alpha_{n}\left[\left\|x_{n}-p\right\|^{2}\right. \\
& +\beta_{n} \gamma_{n}\left(\gamma_{n}^{2} L^{2}+2 \gamma_{n}-1\right)\left\|x_{n}-T_{n} x_{n}\right\|^{2} \\
& \left.+\beta_{n}\left(\beta_{n}-\gamma_{n}\right)\left\|x_{n}-T_{n} z_{n}\right\|^{2}\right] \\
& +\alpha_{n}\left[\left(1-\beta_{n}\right)\left\|x_{n}-T_{n} y_{n}\right\|^{2}+\beta_{n} L^{2}\left(\gamma_{n}-\beta_{n}\right.\right. \\
& \left.\left.+\beta_{n} \gamma_{n} L\right)^{2}\left\|x_{n}-T_{n} x_{n}\right\|^{2}-\beta_{n}\left(1-\beta_{n}\right)\left\|x_{n}-T_{n} z_{n}\right\|^{2}\right] \\
& -\alpha_{n}\left(1-\alpha_{n}\right)\left\|x_{n}-T_{n} y_{n}\right\|^{2} \\
= & \left\|x_{n}-p\right\|^{2}+\left[\alpha_{n} \beta_{n} \gamma_{n}\left(\gamma_{n}^{2} L^{2}+2 \gamma_{n}-1\right)\right. \\
& \left.+\alpha_{n} \beta_{n} L^{2}\left(\gamma_{n}-\beta_{n}+\beta_{n} \gamma_{n} L\right)^{2}\right]\left\|x_{n}-T_{n} x_{n}\right\|^{2}
\end{aligned}
$$




$$
\begin{aligned}
& +\alpha_{n}\left(\alpha_{n}-\beta_{n}\right)\left\|x_{n}-T_{n} y_{n}\right\|^{2} \\
& +\alpha_{n} \beta_{n}\left(2 \beta_{n}-\gamma_{n}-1\right)\left\|x_{n}-T_{n} z_{n}\right\|^{2} .
\end{aligned}
$$

Since from condition (iii), we have that

$$
\begin{gathered}
\gamma\left(\gamma^{2} L^{2}+\gamma L^{2}+2 \gamma-1\right)+\gamma^{2} L^{2}(1+\gamma L)^{2}<0 \\
\Downarrow \\
\gamma_{n}\left(\gamma_{n}^{2} L^{2}+\gamma_{n} L^{2}+2 \gamma_{n}-1\right)+L^{2}\left(\gamma_{n}+\gamma_{n}^{2} L\right)^{2}<0 \\
\Downarrow \\
\alpha_{n} \beta_{n} \gamma_{n}\left(\gamma_{n}^{2} L^{2}+2 \gamma_{n}-1\right)+\alpha_{n} \beta_{n} L^{2}\left(\gamma_{n}-\beta_{n}+\beta_{n} \gamma_{n} L\right)^{2}<0 .
\end{gathered}
$$

Again from condition (i), we have that $\alpha_{n}-\beta_{n} \leq 0$ and $2 \beta_{n}-\gamma_{n}-1 \leq 0$. So, inequality (3.10) implies that

$$
\begin{aligned}
\left\|x_{n+1}-p\right\|^{2} \leq & \left\|x_{n}-p\right\|^{2}-\left[\alpha_{n} \beta_{n} \gamma_{n}\left(1-\gamma_{n}^{2} L^{2}-2 \gamma_{n}\right)\right. \\
& \left.-\alpha_{n} \beta_{n} L^{2}\left(\gamma_{n}-\beta_{n}+\beta_{n} \gamma_{n} L\right)^{2}\right]\left\|x_{n}-T_{n} x_{n}\right\|^{2} .
\end{aligned}
$$

Then

$$
\left\|x_{n+1}-p\right\|^{2} \leq\left\|x_{n}-p\right\|^{2}
$$

It is obviously that $\lim _{n \rightarrow \infty}\left\|x_{n}-p\right\|$ exists, then $\left\{\left\|x_{n}-p\right\|\right\}$ is bounded. This implies that $\left\{x_{n}\right\},\left\{T_{n} x_{n}\right\},\left\{z_{n}\right\},\left\{T_{n} z_{n}\right\},\left\{y_{n}\right\}$ and $\left\{T_{n} y_{n}\right\}$ are also bounded.

Furthermore, from (2.3), we have that

$$
\phi\left(p, x_{n}\right)=\phi\left(p, x_{n+1}\right)+\phi\left(x_{n+1}, x_{n}\right)+2\left\langle x_{n+1}-p, x_{n}-x_{n+1}\right\rangle .
$$

This implies that

$$
\left\langle x_{n+1}-p, x_{n}-x_{n+1}\right\rangle+\frac{1}{2} \phi\left(x_{n+1}, x_{n}\right)=\frac{1}{2}\left(\phi\left(p, x_{n}\right)-\phi\left(p, x_{n+1}\right)\right) .
$$

Moreover, since the interior of $F$ is nonempty, there exists $p^{*} \in F$ and $r>0$ such that $p^{*}+r h \in F$ whenever $\|h\| \leq 1$. Thus, from the fact that $\phi(x, y)=\|x-y\|^{2}$, and (3.12) and (3.13), we get that

$$
\begin{aligned}
0 & \leq\left\langle x_{n+1}-\left(p^{*}+r h\right), x_{n}-x_{n+1}\right\rangle+\frac{1}{2} \phi\left(x_{n+1}, x_{n}\right) \\
& =\frac{1}{2}\left(\phi\left(p^{*}+r h, x_{n}\right)-\phi\left(p^{*}+r h, x_{n+1}\right)\right) .
\end{aligned}
$$

Then from (3.13) and (3.14), we obtain that

$$
\begin{aligned}
r\left\langle h, x_{n}-x_{n+1}\right\rangle & \leq\left\langle x_{n+1}-p^{*}, x_{n}-x_{n+1}\right\rangle+\frac{1}{2} \phi\left(x_{n+1}, x_{n}\right) \\
& =\frac{1}{2}\left(\phi\left(p^{*}, x_{n}\right)-\phi\left(p^{*}, x_{n+1}\right)\right),
\end{aligned}
$$


and hence

$$
\left\langle h, x_{n}-x_{n+1}\right\rangle \leq \frac{1}{2 r}\left(\phi\left(p^{*}, x_{n}\right)-\phi\left(p^{*}, x_{n+1}\right)\right) .
$$

Since $h$ with $\|h\| \leq 1$ is arbitrary, we have

$$
\left\|x_{n}-x_{n+1}\right\| \leq \frac{1}{2 r}\left(\phi\left(p^{*}, x_{n}\right)-\phi\left(p^{*}, x_{n+1}\right)\right) .
$$

So, if $n>m$, then we get that

$$
\begin{aligned}
\left\|x_{m}-x_{n}\right\| & =\left\|x_{m}-x_{m+1}+x_{m+1}-\cdots-x_{n-1}+x_{n-1}-x_{n}\right\| \\
& \leq \sum_{i=m}^{n-1}\left\|x_{i}-x_{i+1}\right\| \\
& \leq \frac{1}{2 r} \sum_{i=m}^{n-1}\left(\phi\left(p^{*}, x_{i}\right)-\phi\left(p^{*}, x_{i+1}\right)\right) \\
& =\frac{1}{2 r}\left(\phi\left(p^{*}, x_{m}\right)-\phi\left(p^{*}, x_{n}\right)\right) .
\end{aligned}
$$

But we know that $\left\{\phi\left(p^{*}, x_{n}\right)\right\}$ converges. Therefore, we obtain that $\left\{x_{n}\right\}$ is a Cauchy sequence. Since $C$ is closed subset of $H$, there exists $x^{*} \in C$ such that

$$
x_{n} \rightarrow x^{*} .
$$

Furthermore, from (3.11) and conditions (i), (ii) and (iii), we get that

$$
\begin{aligned}
\alpha^{3}[ & \left.\left(1-\gamma^{2} L^{2}-2 \gamma\right)-\gamma L^{2}(1+\gamma L)^{2}\right] \sum\left\|x_{n}-T_{n} x_{n}\right\|^{2} \\
\leq & \sum \alpha_{n} \beta_{n} \gamma_{n}\left[\left(1-\gamma_{n}^{2} L^{2}-2 \gamma_{n}\right)-\gamma_{n} L^{2}\left(1+\gamma_{n} L\right)^{2}\right]\left\|x_{n}-T_{n} x_{n}\right\|^{2} \\
= & \sum\left[\alpha_{n} \beta_{n} \gamma_{n}\left(1-\gamma_{n}^{2} L^{2}-2 \gamma_{n}\right)\right. \\
& \left.-\alpha_{n} \beta_{n} \gamma_{n}^{2} L^{2}\left(1+\gamma_{n} L\right)^{2}\right]\left\|x_{n}-T_{n} x_{n}\right\|^{2} \\
\leq & \sum\left[\alpha_{n} \beta_{n} \gamma_{n}\left(1-\gamma_{n}^{2} L^{2}-2 \gamma_{n}\right)\right. \\
& \left.-\alpha_{n} \beta_{n} L^{2}\left(\gamma_{n}-\beta_{n}+\beta_{n} \gamma_{n} L\right)^{2}\right]\left\|x_{n}-T_{n} x_{n}\right\|^{2} \\
\leq & \left\|x_{n+1}-p\right\|^{2}-\left\|x_{n}-p\right\|^{2}<\infty,
\end{aligned}
$$

from which it follows that

$$
\lim _{n \rightarrow}\left\|x_{n}-T_{n} x_{n}\right\|=0 .
$$

Since $\left\{T_{n}\right\}_{n=1}^{\infty}$ are uniformly closed, then from (3.15) and (3.16), we obtain that $x^{*} \in$ $\bigcap_{n=1}^{\infty} F\left(T_{n}\right)=F$. The proof is complete.

Theorem 3.2 Let $C$ be a nonempty, closed and convex subset of a real Hilbert space H, let $T_{n}: C \rightarrow C$ be a finite family of uniformly closed and uniformly Lipschitz pseudocontractive 
mappings with Lipschitzian constants $L_{n}, n=1,2, \ldots, N$. Assume that the interior of $F:=$ $\bigcap_{n=1}^{N} F\left(T_{n}\right)$ is nonempty. Let $\left\{x_{n}\right\}$ be a sequence generated from an arbitrary $x_{0} \in C$ by the following algorithm:

$$
\left\{\begin{array}{l}
z_{n}=\left(1-\gamma_{n}\right) x_{n}+\gamma_{n} T_{n} x_{n}, \\
y_{n}=\left(1-\beta_{n}\right) x_{n}+\beta_{n} T_{n} z_{n}, \\
x_{n+1}=\left(1-\alpha_{n}\right) x_{n}+\alpha_{n} T_{n} y_{n},
\end{array}\right.
$$

where $T_{n}:=T_{n(\bmod N)}$ and $\left\{\alpha_{n}\right\},\left\{\beta_{n}\right\},\left\{\gamma_{n}\right\} \subset(0,1)$ satisfying the following conditions: (i) $\alpha_{n} \leq$ $\beta_{n} \leq \gamma_{n}, \forall n \geq 0$; (ii) $\liminf _{n \infty} \alpha_{n}=\alpha>0$; (iii) $\sup _{n \geq 1} \gamma_{n} \leq \gamma$ with $\gamma^{3} L^{4}+2 \gamma^{2} L^{3}+\gamma^{2} L^{2}+$ $\gamma L^{2}+2 \gamma<1$ for $L:=\max \left\{L_{n}: n=1,2, \ldots, N\right\}$. Then $\left\{x_{n}\right\}$ converges strongly to $x^{*} \in F$.

If in Theorem 3.1, we consider a single Lipschitz pseudocontractive mapping, then we may change the conditions of Theorem 3.1.

Theorem 3.3 Let $C$ be a nonempty, closed and convex subset of a real Hilbert space $H$, let $T: C \rightarrow C$ be a Lipschitz pseudocontractive mappings with Lipschitzian constants $L$. Assume that the interior of $F(T)$ is nonempty. Let $\left\{x_{n}\right\}$ be a sequence generated from an arbitrary $x_{0} \in C$ by the following algorithm:

$$
\left\{\begin{array}{l}
z_{n}=\left(1-\gamma_{n}\right) x_{n}+\gamma_{n} T x_{n} \\
y_{n}=\left(1-\beta_{n}\right) x_{n}+\beta_{n} T z_{n}, \\
x_{n+1}=\left(1-\alpha_{n}\right) x_{n}+\alpha_{n} T y_{n}
\end{array}\right.
$$

where $\left\{\alpha_{n}\right\},\left\{\beta_{n}\right\},\left\{\gamma_{n}\right\} \subset(0,1)$ satisfying the following conditions: (i) $\alpha_{n} \leq \beta_{n} \leq \gamma_{n}, \forall n \geq 0$; (ii) $\sum \alpha_{n} \beta_{n} \gamma_{n}=\infty$; (iii) $\sup _{n \geq 1} \gamma_{n} \leq \gamma$ with $\gamma^{3} L^{4}+2 \gamma^{2} L^{3}+\gamma^{2} L^{2}+\gamma L^{2}+2 \gamma<1$. Then $\left\{x_{n}\right\}$ converges strongly to $x^{*} \in F(T)$.

Proof Following the method of proof of Theorem 3.1, we obtain that $x_{n} \rightarrow x^{*} \in C$.

Furthermore, from (3.10) and conditions (i) and (ii), we obtain (3.11). From (3.11) and conditions (iii) and (iv), we obtain that

$$
\begin{aligned}
& {\left[\left(1-\gamma^{2} L^{2}-2 \gamma\right)-\gamma L^{2}(1+\gamma L)^{2}\right] \sum \alpha_{n} \beta_{n} \gamma_{n}\left\|x_{n}-T_{n} x_{n}\right\|^{2} } \\
& \leq \sum \alpha_{n} \beta_{n} \gamma_{n}\left[\left(1-\gamma_{n}^{2} L^{2}-2 \gamma_{n}\right)-\gamma_{n} L^{2}\left(1+\gamma_{n} L\right)^{2}\right]\left\|x_{n}-T_{n} x_{n}\right\|^{2} \\
&= \sum\left[\alpha_{n} \beta_{n} \gamma_{n}\left(1-\gamma_{n}^{2} L^{2}-2 \gamma_{n}\right)\right. \\
&\left.-\alpha_{n} \beta_{n} \gamma_{n}^{2} L^{2}\left(1+\gamma_{n} L\right)^{2}\right]\left\|x_{n}-T_{n} x_{n}\right\|^{2} \\
& \leq \sum\left[\alpha_{n} \beta_{n} \gamma_{n}\left(1-\gamma_{n}^{2} L^{2}-2 \gamma_{n}\right)\right. \\
&\left.-\alpha_{n} \beta_{n} L^{2}\left(\gamma_{n}-\beta_{n}+\beta_{n} \gamma_{n} L\right)^{2}\right]\left\|x_{n}-T_{n} x_{n}\right\|^{2} \\
& \leq\left\|x_{n+1}-p\right\|^{2}-\left\|x_{n}-p\right\|^{2}<\infty,
\end{aligned}
$$

from which it follows that

$$
\liminf _{n \rightarrow \infty}\left\|x_{n}-T x_{n}\right\|=0
$$


and hence there exists a subsequence $\left\{x_{n_{k}}\right\}$ of $\left\{x_{n}\right\}$ such that

$$
\lim _{n \rightarrow \infty}\left\|T x_{n_{k}}-x_{n_{k}}\right\|=0
$$

Thus, $x_{n_{k}} \rightarrow x^{*}$ and the continuity of $T$ imply that $x^{*}=T x^{*}$, and hence $x^{*} \in F(T)$.

\section{Applications}

Theorem 4.1 Let $H$ be a real Hilbert space, let $\left\{A_{n}\right\}_{n=1}^{\infty}: H \rightarrow H$ be a countable family of uniformly Lipschitz monotone mappings with Lipschitzian constants $L_{n}$, let $L:=$ $\sup _{n \geq 1} L_{n}$. And if $\left\|A_{n} x_{n}\right\| \rightarrow 0, x_{n} \rightarrow x$, then $x \in \bigcap_{n=1}^{\infty} N\left(A_{n}\right)$. Assume that the interior of $F:=\bigcap_{n=1}^{\infty} N\left(A_{n}\right)$ is nonempty. Let $\left\{x_{n}\right\}$ be a sequence generated from an arbitrary $x_{0} \in C$ by the following algorithm:

$$
\left\{\begin{array}{l}
z_{n}=x_{n}-\gamma_{n} A_{n} x_{n}, \\
y_{n}=x_{n}-\beta_{n}\left(x_{n}-z_{n}\right)-\beta_{n} A_{n} z_{n}, \\
x_{n+1}=x_{n}-\alpha_{n}\left(x_{n}-y_{n}\right)-\alpha_{n} A_{n} y_{n},
\end{array}\right.
$$

where $\left\{\alpha_{n}\right\},\left\{\beta_{n}\right\},\left\{\gamma_{n}\right\} \subset(0,1)$ satisfying the following conditions: (i) $\alpha_{n} \leq \beta_{n} \leq \gamma_{n}, \forall n \geq 0$; (ii) $\liminf _{n \infty} \alpha_{n}=\alpha>0$; (iii) $\sup _{n \geq 1} \gamma_{n} \leq \gamma$ with $\gamma^{3} L^{4}+2 \gamma^{2} L^{3}+\gamma^{2} L^{2}+\gamma L^{2}+2 \gamma<1$. Then $\left\{x_{n}\right\}$ converges strongly to $x^{*} \in F$.

Proof Suppose that $T_{n} x:=\left(I-A_{n}\right) x$ for $n \geq 1$. Then we get that $\left\{T_{n}\right\}_{n \geq 1}$ is a countable family of uniformly closed and uniformly Lipschitz pseudocontractive mappings with $\bigcap_{n=1}^{\infty} F\left(T_{n}\right)=\bigcap_{n=1}^{\infty} N\left(A_{n}\right) \neq \emptyset$. Moreover, when $A_{n}$ is replaced by $I-T_{n}$, Scheme (4.1) reduces to Scheme (3.1) and hence the conclusion follows from Theorem 3.1.

Corollary 4.2 Let $H$ be a real Hilbert space, let $A_{n}: H \rightarrow H$ be a finite family of uniformly Lipschitz monotone mappings with Lipschitzian constants $L_{n}, n=1,2, \ldots, N$. And if $\left\|A_{n} x_{n}\right\| \rightarrow 0, x_{n} \rightarrow x$, then $x \in \bigcap_{n=1}^{N} N\left(A_{n}\right)$. Assume that the interior of $F:=\bigcap_{n=1}^{N} N\left(A_{n}\right)$ is nonempty. Let $\left\{x_{n}\right\}$ be a sequence generated from an arbitrary $x_{0} \in C$ by the following algorithm:

$$
\left\{\begin{array}{l}
z_{n}=x_{n}-\gamma_{n} A_{n} x_{n}, \\
y_{n}=x_{n}-\beta_{n}\left(x_{n}-z_{n}\right)-\beta_{n} A_{n} z_{n}, \\
x_{n+1}=x_{n}-\alpha_{n}\left(x_{n}-y_{n}\right)-\alpha_{n} A_{n} y_{n},
\end{array}\right.
$$

where $A_{n}:=A_{n(\bmod N)}$ and $\left\{\alpha_{n}\right\},\left\{\beta_{n}\right\},\left\{\gamma_{n}\right\} \subset(0,1)$ satisfying the following conditions: (i) $\alpha_{n} \leq$ $\beta_{n} \leq \gamma_{n}, \forall n \geq 0$; (ii) $\liminf _{n \infty} \alpha_{n}=\alpha>0$; (iii) $\sup _{n \geq 1} \gamma_{n} \leq \gamma$ with $\gamma^{3} L^{4}+2 \gamma^{2} L^{3}+\gamma^{2} L^{2}+$ $\gamma L^{2}+2 \gamma<1$ for $L:=\max \left\{L_{n}: n=1,2, \ldots, N\right\}$. Then $\left\{x_{n}\right\}$ converges strongly to $x^{*} \in F$.

Corollary 4.3 Let $H$ be a real Hilbert space, let $A: H \rightarrow H$ be a Lipschitz monotone mappings with Lipschitzian constants L. Assume that the interior of $N(A)$ is nonempty. Let $\left\{x_{n}\right\}$ be a sequence generated from an arbitrary $x_{0} \in C$ by the following algorithm:

$$
\left\{\begin{array}{l}
z_{n}=x_{n}-\gamma_{n} A x_{n}, \\
y_{n}=x_{n}-\beta_{n}\left(x_{n}-z_{n}\right)-\beta_{n} A z_{n}, \\
x_{n+1}=x_{n}-\alpha_{n}\left(x_{n}-y_{n}\right)-\alpha_{n} A y_{n},
\end{array}\right.
$$


where $\left\{\alpha_{n}\right\},\left\{\beta_{n}\right\},\left\{\gamma_{n}\right\} \subset(0,1)$ satisfying the following conditions: (i) $\alpha_{n} \leq \beta_{n} \leq \gamma_{n}, \forall n \geq 0$; (ii) $\sum \alpha_{n} \beta_{n} \gamma_{n}=\infty$; (iii) $\sup _{n \geq 1} \gamma_{n} \leq \gamma$ with $\gamma^{3} L^{4}+2 \gamma^{2} L^{3}+\gamma^{2} L^{2}+\gamma L^{2}+2 \gamma<1$. Then $\left\{x_{n}\right\}$ converges strongly to $x^{*} \in N(A)$.

Remark 4.4 In the paper [18], Scheme (2.28) of Theorem 2.5 and Scheme (2.29) of Corollary 2.6 are not correct, they are replaced by the following iterative algorithms, respectively.

$$
\left\{\begin{array}{l}
y_{n}=x_{n}-\beta_{n} A_{n} x_{n}, \\
x_{n+1}=x_{n}-\alpha_{n}\left(x_{n}-y_{n}\right)-\alpha_{n} A_{n} y_{n},
\end{array}\right.
$$

and

$$
\left\{\begin{array}{l}
y_{n}=x_{n}-\beta_{n} A x_{n}, \\
x_{n+1}=x_{n}-\alpha_{n}\left(x_{n}-y_{n}\right)-\alpha_{n} A y_{n} .
\end{array}\right.
$$

\section{Competing interests}

The authors declare that they have no competing interests.

\section{Authors' contributions}

All authors contributed equally and significantly in writing this article. All authors read and approved the final manuscript

\section{Acknowledgements}

This project is supported by the National Natural Science Foundation of China under grant (11071279).

Received: 14 January 2013 Accepted: 3 April 2013 Published: 17 April 2013

\section{References}

1. Browder, FE, Petryshyn, WV: Construction of fixed points of nonlinear mappings in Hilbert spaces. J. Math. Anal. Appl. 20, 197-228 (1967)

2. Zeidler, E: Nonlinear Functional Analysis and Its Applications, Part II: Monotone Operators. Springer, Berlin (1985)

3. Chidume, $C E$, Moore, $\mathrm{C}$ : The solution by iteration of nonlinear equations in uniformly smooth Banach spaces. J. Math. Anal. Appl. 215, 132-146 (1997)

4. Liu, Q: The convergence theorems of the sequence of Ishikawa iterates for hemi-con tractive mappings. J. Math. Anal. Appl. 148, 55-62 (1990)

5. Zhang, S: On the convergence problems of Ishikawa and Mann iteration processes with error for $\phi$-pseudocontractive type mappings. Appl. Math. Mech. 21, 1-10 (2000)

6. Mann, WR: Mean value methods in iteration. Proc. Am. Math. Soc. 4, 506-510 (1953)

7. Chidume, CE, Mutangadura, SA: An example of the Mann iteration method for Lipschitz pseudocontractions. Proc. Am. Math. Soc. 129, 2359-2363 (2001)

8. Ishikawa, S: Fixed points by a new iteration method. Proc. Am. Math. Soc. 44, 147-150 (1974)

9. Chidume, CE, Moore, C: Fixed point iteration for pseudocontractive maps. Proc. Am. Math. Soc. 127, 1163-1170 (1999)

10. Liu, Q: On Naimpally and Singh's open question. J. Math. Anal. Appl. 124, 157-164 (1987)

11. Zhou, H: Convergence theorems of fixed points for Lipschitz pseudo-contractions in Hilbert spaces. J. Math. Anal. Appl. 343, 546-556 (2008)

12. Yao, YH, Liou, YC, Marino, G: A hybrid algorithm for pseudo-contractive mappings. Nonlinear Anal. 71, 4997-5002 (2009)

13. Tang, YC, Peng, JG, Liu, LW: Strong convergence theorem for pseudo-contractive mappings in Hilbert spaces. Nonlinear Anal. 74, 380-385 (2011)

14. Zhou, $\mathrm{H}$ : Convergence theorems for $\lambda$-strict pseudocontractions in 2-uniformly smooth Banach spaces. Nonlinear Anal. 69, 3160-3173 (2008)

15. Alber, Y: Metric and generalized projection operators in Banach spaces: properties and applications. In: Kartsatos, AG (ed.) Theory and Applications of Nonlinear Operators of Accretive and Monotone Type. Lecture Notes in Pure and Appl. Math., vol. 178, pp. 15-50. Dekker, New York (1996)

16. Kamimura, S, Takahashi, W: Strong convergence of proximal-type algorithm in a Banach space. SIAM J. Optim. 13, 938-945 (2002)

17. Reich, S: A weak convergence theorem for the alternating method with Bergman distance. In: Kartsatos, AG (ed.) Theory and Applications of Nonlinear Operators of Accretive and Monotone Type. Lecture Notes in Pure and Appl. Math., vol. 178, pp. 313-318. Dekker, New York (1996)

18. Zegeye, H, Shahzad, N, Alghamdi, MA: Convergence of Ishikawa's iteration method for pseudocontractive mappings. Nonlinear Anal. 74, 7304-7311 (2011) 
doi:10.1186/1687-1812-2013-100

Cite this article as: Cheng et al.: Convergence theorems of a three-step iteration method for a countable family of pseudocontractive mappings. Fixed Point Theory and Applications 2013 2013:100.

Submit your manuscript to a SpringerOpen ${ }^{\circ}$ journal and benefit from:

- Convenient online submission

- Rigorous peer review

- Immediate publication on acceptance

Open access: articles freely available online

- High visibility within the field

- Retaining the copyright to your article

Submit your next manuscript at $\gg$ springeropen.com 